\title{
Photoinduced Synthesis of Antibacterial Hydrogel from Aqueous Photoinitiating System
}

Pauline Sautrot-Ba ${ }^{1}$, Steffen Jockusch ${ }^{2}$, Thi-Thanh-Tam Nguyen ${ }^{1}$, Daniel Grande ${ }^{1}$, Annalisa Chiapionne $^{3}$, S. Abbad-Andaloussi ${ }^{4}$, Miaobo Pan $^{5}$, Rachel Méallet-Renault ${ }^{5}$, Davy-Louis Versace $^{1 *}$

${ }^{1}$ Institut de Chimie et des Matériaux Paris-Est, UPEC, UMR-CNRS 7182, Département C3M, 2-8 rue Henri Dunant 94320 Thiais

${ }^{2}$ Department of Chemistry, Columbia University, 3000 Broadway, New York, NY 10027, United States.

${ }^{3}$ Politechnico di Torino, Dipartimento di Scienza Applicata e Tecnologia, C. so Duca degli Abruzzi 24, 10129 Torino, Italy

${ }^{4}$ Université Paris-Est Créteil (UPEC), Laboratoire Eau, Environnement, Systèmes Urbains (LEESU), UMR-MA 102, 61 avenue Général de Gaulle, 94010 Créteil Cedex, France.

${ }^{5}$ Université Paris-Saclay, CNRS, Institut des Sciences Moléculaires d'Orsay, 91405, Orsay, France.

Abstract. A new photoactivable material based on polyethylene imine with allyl functions (APEI monomer) was synthesized to develop new hydrogel. The water-based photoinitiating system consisting of anthraquinone-2-sulfonic acid (AQS) and $N$-methyldiethanol amine (MDEA) was studied by laser flash photolysis and electron paramagnetic resonance. LED@ 385 $\mathrm{nm}$ exposure of this combination of AQS with MDEA in aqueous medium has led to the formation of $\alpha$-aminoalkyl radicals which were able to cross-link the acrylamide and A-PEI to generate new antibacterial materials in reduced time and under air. Interestingly, the addition of the multifunctional A-PEI monomer to acrylamide derived monomers has led to faster gel formation and an increase of the instantaneous $G^{\prime}$ modulus value. The resulting hydrogel containing quaternary ammonium groups on its surface has demonstrated excellent antiadherence and biocide properties against Escherichia coli and Staphylococcus aureus.

Keywords: Aqueous photoinitiating system; Antibacterial material; Free-radical polymerization; UV-light. 


\section{Introduction}

For years nosocomial diseases have been a scourge for hospitals and their patients. Two million patients suffer from nosocomial infections during their hospital stays annually in the US, and nearly 90,000 deaths. In the UK, 300,000 people acquire infections in hospitals each year, resulting in nearly 5,000 deaths. In addition to these alarming statistics, more than $£ 1$ billion per year in UK and at least $\$ 10$ billion annually in the US are spent on the struggle against hospital-acquired infections according to the Office for National Statistics and these costs come directly out of the hospital's budget [1-3]. The spread of micro-organisms should be urgently limited because it is estimated that the mortality rate will become higher than those of cancers or road accidents and may reach more than 10 million per year in 2050, increasing thus the health care costs and social security debt $[4,5]$.

Scientists are competing in ingenuity to develop innovative strategies that are increasingly original and effective against resistant bacteria to eradicate these nosocomial diseases [6-16]. Numerous reviews [17-22] on the subject have been published. Anti-bacterial materials could be considered as (i) biocides materials when bacteria are killed in contact to surfaces or killed by biocidal agents released from the materials (these are considered as "active materials") and (ii) anti-fouling materials when adhesion and proliferation of bacteria onto a surface are prevented (called "passive materials"). Among the "active strategies", the use of reactive oxygen species [7, 9], polymers with quaternary ammonium functions [23, 24], guanidine polymers [25], polymers which mimic natural peptides [26, 27], phospho- and sulfoderived polymers [28, 29], phenol and benzoic acid derived polymers [15], polyelectrolyte multilayers [30], and more recently the release of inorganic antimicrobial compounds [11, 12, 31, 32] (zinc oxide, $\mathrm{TiO}_{2}$, montmorillonite-derivative clays, and metal nanoparticles) have been mostly described in literature, whereas the "passive method" [33, 34] emphasizes the use of PEG-containing or fluorinated coatings.

Among all the developed strategies, hydrogels i.e. three-dimensional cross-linked polymeric networks, have been considered as good candidates for effective antimicrobial applications. Outstanding reviews have already been published with regards to this topic [3537]. Hydrogels can exhibit antimicrobial properties when introducing antimicrobial agents (e.g. $\mathrm{Ag}, \mathrm{ZnO}$ nanoparticles, antibiotics) which could be controlled released or have inherent antibacterial activities when natural cationic polymers, antimicrobial peptides, or polycationic petro-sourced polymers are incorporated. According to the development of antimicrobial agents, the progresses of antimicrobial hydrogels in the last decade have been remarkably 
exploited in many pharmaceutical and medical applications [38] as disinfectants, personal care products, sanitizers, catheter coatings, wound dressings, dental and gastrointestinal materials against infections, contact lens or prosthetic implants. Clinical studies have even highlighted the main role played by hydrogels for improving the healing process around the wound site by protecting damaged skin from cellular dehydration and angiogenesis [37].

Interestingly, most of these studies concern the synthesis of original antibacterial hydrogels [39] via thermal process and a few describe the synthesis of antibacterial hydrogels by photochemistry [40-43]. Yet, photochemistry is now well recognized as a green method and has attracted great attention because it offers many advantages $[44,45]$ such as $(i)$ rapid cure (a few seconds or minutes), permitting high production rate; (ii) low energy requirements as curing can be done at very low light intensities; (iii) photo-curing can be performed at room temperature and below, which is suitable for heat-sensitive supports; (iv) the absence of organic solvent, avoiding the release of volatile organic compounds; $(v)$ application versatility, small space requirements, easy to use, with low investment; (vi) low level of waste; (vii) moderate costs of photo-initiating systems; and (viii) spatio-temporal control. All these aspects justify the fast growth and the increasing interest of photochemistry as a green technique in the context of sustainable development.

The aim of this work is therefore to prepare antibacterial gels via photochemical processes in a reduced time, in aqueous conditions with the use of an aqueous photoinitiating system, by combining acrylamide- and modified polyethyleneimine (PEI) based monomers. Modified PEI play a dual role i.e. as crosslinker and as antibacterial agent with the presence of quaternary ammonium (QA) groups. The introduction of QA into materials was recently reviewed as a great potential strategy to develop safe antibacterial surfaces [46-50]. Their high antibacterial efficiency come from an interaction between their positive charge, which make them likely to interact with the negatively charged cell wall of the outer membrane of Grampositive and Gram-negative cells, and their amphiphilic character, inducing the membrane disruption and the bacterial death. As a consequence, QA derivatives appear as interesting molecules for developing new performing antibacterial materials. The reactivity of a new waterbased photoinitiating system containing anthraquinone-2-sulfonic acid (AQS) and $\mathrm{N}$ methyldiethanol amine (MDEA) has been studied in detail by laser flash photolysis (LFP) and Electron Paramagnetic Resonance (EPR), and Real-Time Fourier Transform Infrared spectroscopy (RT-FTIR). Furthermore, photo-rheology and X-Ray photoelectron spectroscopy (XPS) were used to characterize and understand the behavior of the corresponding water-based gels under light activation. Finally, the antibacterial properties (anti-fouling and biocide 
activities) of the resulting photo-crosslinked hydrogels have been studied by anti-adherence tests and fluorescence microscopy.

\section{Experimental part}

Materials. Acrylamide, N,N-Bisacrylamide, polyethylene imine (PEI), anthraquinone-2sulfonic acid (AQS) and $N$-methyldiethanol amine (MDEA) were purchased from SigmaAldrich. Polyethylene glycol diacrylate (PEG-DA, $\mathrm{M}_{\mathrm{n}}=596 \mathrm{~g} / \mathrm{mol}, \mathrm{SR} 344$ ) was kindly provided by Sartomer. The chemical structures of the main compounds used in this study are shown in Table 1.

Table 1. Chemical structures of the monomers and photoinitiating systems used in this study.

\begin{tabular}{lll}
\hline \multicolumn{1}{c}{ Name } & \\
Acrylamide & Anthraquinone-2-sulfonic acid (AQS) \\
Polyethylene imine (PEI) & -misacrylamide
\end{tabular}

Synthesis of the allylated PEI-HCI (A-PEI). A mixture of branched PEI $\left(M_{\mathrm{n}}=10.000 \mathrm{~g} \times\right.$ $\mathrm{mol}^{-1}, M_{\mathrm{w}} / M_{\mathrm{n}}=2.5,6.7 \mathrm{~g}, \sim 50,8 \mathrm{mmol}$ of repetitive monomer units) in $50 \mathrm{~mL}$ dichloromethane was stirred at room temperature (until a homogeneous solution formed) before adding allyl bromide $(2.2 \mathrm{~mL}, 25.4 \mathrm{mmol})$. The reaction mixture was stirred overnight under argon atmosphere followed by solvent evaporation. The resulting viscous allylated PEI (partially 
protonated by the generated $\mathrm{HBr}$ ) was dissolved in $30 \mathrm{~mL}$ of distilled water, cooled to $0{ }^{\circ} \mathrm{C}$ and acidified to $\mathrm{pH} 2$ using a $1 \mathrm{M} \mathrm{HCl}$ aqueous solution. Then, water and excess of $\mathrm{HCl}$ was removed by evaporation on a rotary evaporator at $50{ }^{\circ} \mathrm{C}$. In a last step, the remaining trace of water was completely removed by lyophilisation. The completely protonated (A-PEI) was obtained in a quantitative yield as a slight yellow solid $(9.7 \mathrm{~g}, 99 \%)$. This positively charged polymer product is very hygroscopic and thus can absorb water moisture quickly to yield highly viscous resin like materials (difficult to be handled). As such, the final product should be stored under inert atmosphere in the fridge for easy handling.

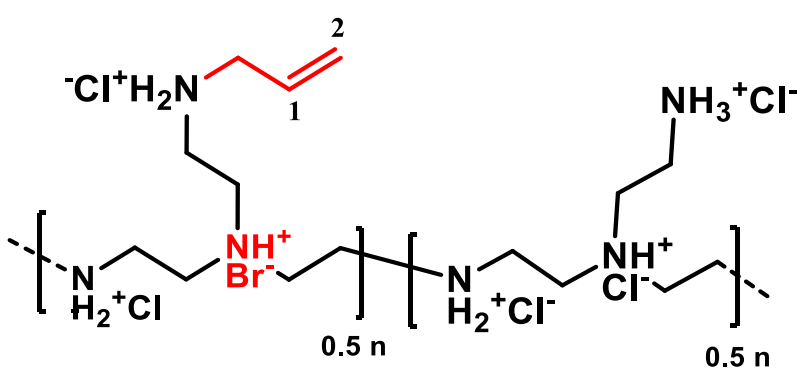

Scheme 1. Chemical structure of A-PEI

${ }^{1} \mathbf{H}$ NMR $\left(\mathrm{D}_{2} \mathrm{O}, 400 \mathrm{MHz}\right) \delta$ 5.9-5.4 (1.5 H, $\left.\mathrm{H}^{1}+\mathrm{H}^{2}\right), 4.0-2.7(13 \mathrm{H})$ ppm. ${ }^{13} \mathbf{C}$ NMR $\left(\mathrm{D}_{2} \mathrm{O}, 100\right.$ $\mathrm{MHz}) \delta 129.2\left(\mathrm{C}^{1}\right), 125.3\left(\mathrm{C}^{2}\right), 56.8,50.2,49.3,45.6,43.8,42.5,36.8,35.9,34.3$ ppm. . ATRFTIR $\approx 3400$ (broad, NH), 2500-300 (broad, $v_{\mathrm{N}-\mathrm{H}}$ in $\mathrm{NH}_{4}{ }^{+} \& v_{\mathrm{CH}}$ in $\mathrm{CH}_{2}$ ), 1599 (NH bending), $1575\left(v_{\mathrm{C}=\mathrm{C}}\right), 991\left(\delta_{\text {out of plan }}-\mathrm{CH}=\mathbf{C H}_{2}\right), 959\left(\delta_{\text {out of plan }}-\mathbf{C H}=\mathrm{CH}_{2}\right), 770(\mathrm{C}-\mathrm{H}$ bending $) \mathrm{cm}^{-1}$. Yield $=99 \%$.

FTIR-ATR spectroscopy. FT-IR spectra were recorded on a Nicolet Magna-IR 550 spectrometer using the attenuated total reflection (ATR) mode between 4000 and $450 \mathrm{~cm}^{-1}$ with an average of 32 consecutive scans and a resolution of $4 \mathrm{~cm}^{-1}$.

NMR spectroscopy. ${ }^{1} \mathrm{H}$ NMR and ${ }^{13} \mathrm{CNMR}$ spectra were recorded on a Bruker Avance III spectrometer with an operating frequency of $400 \mathrm{MHz}$ and $100 \mathrm{MHz}$, respectively.

Real-Time Fourier Transform InfraRed Spectroscopy (RT-FTIR). PEG-DA formulation has been laid on $\mathrm{BaF}_{2}$ chip and irradiated under air or in laminated conditions upon LED@ 385 $\mathrm{nm}$ exposure. The decrease of the acrylate function of PEG-DA was continuously followed by RT-FTIR (JASCO FTIR 4100) at $1636 \mathrm{~cm}^{-1}$ with AQS/MDEA $(1 \% / 6 \% \mathrm{w} / \mathrm{w})$

Laser Flash Photolysis. Laser flash photolysis experiments employed the pulses from a Spectra Physics GCR-150-30 Nd:YAG laser (355 nm, 7 ns pulse length) and a computer controlled system that has been described elsewhere [51]. For recording the transient absorption 
spectra and quenching studies, solutions of AQS were prepared at concentrations such that the absorbance was $\sim 0.3$ at the excitation wavelength $(355 \mathrm{~nm})$ at a path length of $1 \mathrm{~cm}$.

Electron Paramagnetic Resonance. EPR measurements were performed at room temperature on a Bruker EMX spectrometer operating at X-band $(9.5 \mathrm{GHz})$. Argon saturated aqueous solutions of AQS in the absence and presence of MDEA were flowed through the cavity of the EPR resonator and were irradiated with a $300 \mathrm{~W}$ Xe lamp (ILC Technologies, Inc.).

Rheological experiments. Real-Time rheological measurements have been performed using an Anton Paar rheometer (MCR 302) in parallel plate mode with a Hamamatsu LC8 lamp with UV bulb equipped with $8 \mathrm{~mm}$ light guide (UV-A intensity $=25 \mathrm{~mW} / \mathrm{cm}^{2}$ ). The gap between the two plates was set to $0.2 \mathrm{~mm}$ and the sample was kept at a constant temperature $\left(25^{\circ} \mathrm{C}\right)$. The variation of the elastic component of the modulus, G', was followed during the light induced polymerization as a function of exposure time. Time sweep tests were performed at constant shear frequency of $1 \mathrm{~Hz}$ with a strain amplitude of $1 \%$ (in the linear viscoelastic region).

Synthesis of the hydrogels. Two hydrogels were synthesized under LED@385 nm exposure $\left(130 \mathrm{~mW} / \mathrm{cm}^{2}\right)$ during $20 \mathrm{~min}$. The first one is considered as a reference ("R-Acryl") and contains bisacrylamide (5 mg)/ acrylamide (50 mg) / AQS (1 mg) / MDEA (10 mg) in $200 \mu \mathrm{l}$ of water. In the second one, $40 \mathrm{mg}$ of A-PEI is additionally introduced into the reference formulation and is labelled "A-PEI".

Network parameters [40]. Mc, which corresponds to the molar mass between two adjacent crosslinks, can be calculated using Flory-Huggins theory (equation 1).

$\mathrm{Mc}=\left(-\mathrm{d}_{\mathrm{p}} \mathrm{V}_{\mathrm{s}} \emptyset^{1 / 3}\right) /\left(\ln (1-\varnothing)+\emptyset+\chi \emptyset^{2}\right)$

where $d_{p}$ is the polymer density (1.3), $V_{s}$ is the molar volume of water $\left(18 \mathrm{~cm}^{3} \times \mathrm{mol}^{-1}\right), \varnothing$ is the volume fraction of the polymer in the hydrogel, $\chi$ is the Flory-Huggins polymer-solvent interaction parameter (0.4).

The volume fraction of the polymer, $\varnothing$, in the swollen state, can be described as equation 2 :

$\varnothing=\left(1+\left(\mathrm{d}_{\mathrm{p}} / \mathrm{d}_{\mathrm{s}}\right) \times\left(\mathrm{m}_{\mathrm{o}} / \mathrm{m}_{\mathrm{f}}\right)-\mathrm{d}_{\mathrm{p}} / \mathrm{d}_{\mathrm{s}}\right)$

where $m_{0}$ and $m_{f}$ are the mass of the polymer before and after swelling, respectively, and $d_{s}$ is the density of the solvent.

Water swelling behaviour. The swelling characteristics of acrylamide-based hydrogels were estimated by immersing dried samples in $10 \mathrm{~mL}$ distilled water for few hours. Every hour the samples were removed from the swelling medium and blotted with a piece of paper to remove excess water on the substrate and weighted. The swelling ratio $\left(100^{*} \mathrm{~m}_{t} / \mathrm{m}_{0}\right)$, where $\mathrm{m}_{0}$ and $\mathrm{m}_{\mathrm{t}}$ correspond to the weight of the dried and swollen samples, were determined and the water content at equilibrium was calculated from eq. 3 : 
$\mathrm{Q}_{\mathrm{H} 2 \mathrm{O}}=100 \times\left(\mathrm{m}_{\mathrm{t}}-\mathrm{m}_{0}\right) / \mathrm{m}_{\mathrm{t}}$

X-Ray photoelectron spectroscopy (XPS). XPS measurements were performed using a Kalpha Thermo Scientific photoelectron spectrometer with monochromatized Al Ka excitation ( $\mathrm{h} v=1486.6 \mathrm{eV}$ ) according to references. The composition of the materials was evaluated by measuring integrated photo-peaks intensities after a Shirley background subtraction. The peaks areas were corrected from sensitivity factors. $400 \mu \mathrm{m}$ is the diameter of the X-ray spot. Survey spectra were acquired from 0 to $1200 \mathrm{eV}$, with a pass energy of $200 \mathrm{eV}$ and an energy step of $1.0 \mathrm{eV}$. The high-resolution spectrum of the N1s was obtained with a pass energy of $50 \mathrm{eV}$ with a $0.01 \mathrm{eV}$ energy step. Prior to the measurements, the analysis chamber base pressure should reach $8.010^{-10}$ torr. Electron flood gun combined with an argon ion gun allow the charge compensation.

Anti-adherence tests. Antibacterial experiments on both hydrogels (with and without allylated PEI-HCl) against Escherichia coli (E. coli ATCC25922) and Staphylococcus aureus (S. aureus ATCC6538) were performed according to a previously described method [52] after $3 \mathrm{~h}$ of incubation. Experiments were conducted on three to five different materials to get statistics.

Confocal laser scanning microscopy. Fluorescence images were acquired using Leica TCS SP5-AOBS confocal laser scanning microscope according to reference [8]. The surfaces were imaged using a $\times 63-1.4$ numerical aperture plan apochromat oil immersion objective. The size of the xy image was $1024 \times 1024$ pixels recorded on 12 bits. Prior to each observation, bacteria were stained with $100 \mu \mathrm{g} / \mathrm{mL}$ of Propidium iodide (PI, Life Technologies, France), and $5 \mu \mathrm{M}$ of Syto 9 (Life Technologies, France). The PI and Syto 9 were sequentially excited at 543 and $476 \mathrm{~nm}$, respectively. Fluorescence emissions were collected between $500 \mathrm{~nm}$ and $600 \mathrm{~nm}$ for Syto 9 (green fluorescence, both live and dead cells), $620 \mathrm{~nm}$ and $750 \mathrm{~nm}$ for PI (red fluorescence, only dead cells).

\section{Results and discussion}

Synthesis of A-PEI. The complete procedure for the synthesis of the A-PEI is described in Figure 1, and the ${ }^{1} \mathrm{H}$ and ${ }^{13} \mathrm{C}$ NMR spectra of this corresponding compound are displayed in Supporting Information (Figures S1 and S2). Allylation of branched PEI occurs according to a previously reported procedure [53]. It has been known that simple amines can act both as a base and a nucleophile, and allows them to undergo nucleophilic substitutions on electrophile species. In this regard, the partially A-PEI intermediates were easily accessible using allyl bromide as an electrophile reagent and neutral branched PEI as "polynucleophiles" (Figure 1 - 
step 1). The reaction was completed after $24 \mathrm{~h}$ at room temperature. Before removing solvent, the resulting A-PEI was completely protonated by an additional acidification step (Figure 1 step 2) to avoid the physical and chemical crosslinking between polymer chains. The purification of the crude by evaporation and lyophylisation gave the expected product in a good yield $(99 \%)$. Since the conversion of this substitution reaction is quantitative, the allylation ratio could be easily controlled by adjusting the amount of allylbromide. In this study, the degree of allylation (DA) of PEI was chosen to be as high as possible, i.e. $\sim 50 \%$, in order to: (i) increase the proportion of tertiary ammonium ion in the final allylated product since this type of ammonium ion has been known to exhibit higher antibacterial properties than the secondary or primary amines and (ii) increase the number of double bonds in the final product which would enable to prepare highly robust antibacterial films according to the increasing number of possible crosslinking. ${ }^{1} \mathrm{H}$ NMR analysis of the allylated PEI-HCl confirms the presence of allylic groups [53, 54] whose ${ }^{1} \mathrm{H}$ NMR signals (Figure S1) appear at 5.4-5.9 ppm $\left(\mathrm{m}, 1.5 \mathrm{H},-\mathrm{CH}=\mathrm{CH}_{2}\right)$, and $4.0 \mathrm{ppm}\left(1 \mathrm{H},-\mathrm{CH}_{2}-\mathrm{CH}=\mathrm{CH}_{2}\right)$ and ${ }^{13} \mathrm{C}$ NMR signals (Figure $\left.\mathrm{S} 2\right)$ 125.0-129.0 ppm $\left(-\mathrm{CH}=\mathrm{CH}_{2}\right)$ and $56 \mathrm{ppm} \quad\left(-\mathrm{CH}_{2}-\mathrm{CH}=\mathrm{CH}_{2}\right)$. This side-chain allyl functionalization was further confirmed by FTIR analysis (Figure S3), especially by the appearance of a strong band (doublet) between 950 and $990 \mathrm{~cm}^{-1}$ attributed to out-of plane bending of allylic protons.

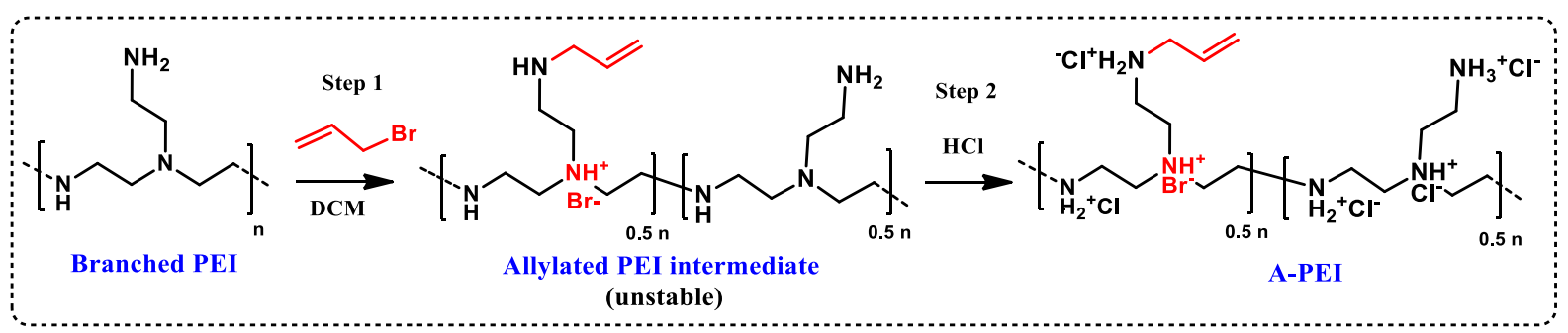

Figure 1. Synthesis of A-PEI

Photoreactivity of the AQS/MDEA aqueous system. To avoid the release of volatile organic compounds (VOCs), the addition of any solvent is required; water should be preferentially used without decreasing the initiating performances of the photoinitiating systems. In the following section, a new water-based photoinitiating system i.e. AQS/MDEA was studied by LFP, EPR and RT-FTIR experiments. AQS, a water soluble anthraquinone derivative shows strong light absorption in the near-UV. Therefore, making it suitable in applications using modern light sources based on purple LEDs $(385 \mathrm{~nm})$. After photoexcitation, anthraquinones undergo efficient intersystem crossing into the triplet state. The triplet state reactivity of AQS was 
studied by laser flash photolysis. Figure 2 shows the transient absorption spectra of AQS in deoxygenated water solution after pulsed laser excitation $(355 \mathrm{~nm})$. The transient absorption at the end of the laser pulse (red spectrum) was assigned to the triplet state, ${ }^{3} \mathrm{AQS}^{*}$, based on the literature $[55,56]$. The triplet decayed under our experimental condition with a lifetime of $0.2 \mu \mathrm{s}$. In addition, at longer time scales (blue spectrum) a long-lived transient was observed. The nature of this transient is believed to be an adduct of ${ }^{3} \mathrm{AQS}^{*}$ and water [55-58]. The triplet states, ${ }^{3} \mathrm{AQS} *$, were efficiently quenched by the co-initiator, MDEA. The bimolecular rate constant for this reaction was determined from the plot of the slope of the inverse triplet lifetime $v s$ the concentration of MDEA (Figure S4). The high rate constant $\left(\mathrm{k}_{\mathrm{q}}{ }^{\text {MDEA }}=8.1 \times 10^{9} \mathrm{M}^{-1} \mathrm{~s}^{-1}\right)$ ensures efficient reaction with the co-initiator. The reaction product was investigated by laser flash photolysis. Figure 3 shows the transient absorption after reaction of ${ }^{3} \mathrm{AQS} *$ with MDEA. The transient was assigned to the AQS radical anion $\left(\mathrm{AQS}^{\circ-}\right)$ based on literature spectra [59, 60]. The $\alpha$-aminoalkyl radical of MDEA, which is also generated in this reaction, is not observable in the transient spectrum due to its low extinction coefficient.

Further experimental evidence for efficient radical formation was given by EPR spectroscopy. A strong EPR signal was observed when deoxygenated aqueous solutions of AQS were irradiated with UV light in the presence of MDEA (Figure 4). The spectrum is dominated by the long-lived AQS radical anion (AQS ${ }^{\bullet-}$ ). In the absence of MDEA the EPR signal was negligible during irradiation.

The high initiating efficiency of AQS/MDEA was demonstrated by RT-FTIR by following the acrylate absorbance $\left(1636 \mathrm{~cm}^{-1}\right)$ of PEG-DA (used as a reference) upon LED@385nm exposure under air and in laminate (Figure S5). Despite the oxygen inhibition is a serious concern in free-radical polymerization (FRP), i.e. oxygen reacts with radical species to form peroxyl radicals (ROO•) which are unable to initiate the FRP, the kinetic profile of PEG-DA with AQS/MDEA system (Figure S5) is much more efficient under air than in laminate. Indeed, this interesting result could be explained by (i) the formation of highly reactive $\alpha$-aminoalkyl radicals, (ii) $\mathrm{k}_{\mathrm{q}}{ }^{\mathrm{MDEA}}\left({ }^{3} \mathrm{AQS}\right)$ is higher than $\mathrm{k}_{\mathrm{q}}{ }^{\mathrm{O} 2}\left({ }^{3} \mathrm{AQS}\right)$ (Figure $\mathrm{S} 6$ ), which prompt ${ }^{3} \mathrm{AQS}$ to preferentially react with MDEA than $\mathrm{O}_{2}$, and (iii) some oxygen in the system might be beneficial, because AQS radical anion $\left(\mathrm{AQS}^{{ }^{-}}\right)$get oxidized to AQS by molecular oxygen, re-generating the chromophore with $\mathrm{k}_{\mathrm{q}}{ }^{\mathrm{O}}\left(\mathrm{AQS}^{\cdot-}\right)=1.45 \pm 0.05 \times 10^{9} \mathrm{M}^{-1} \mathrm{~s}^{-}$ ${ }^{1}$ (Figure S6). The re-generation of AQS from $\mathrm{AQS}^{{ }^{--}}$by $\mathrm{O}_{2}$ can be observed in Figure S7. Therefore, such a photoinitiating system could be then envisaged for the synthesis of antibacterial hydrogel in aqueous medium. 

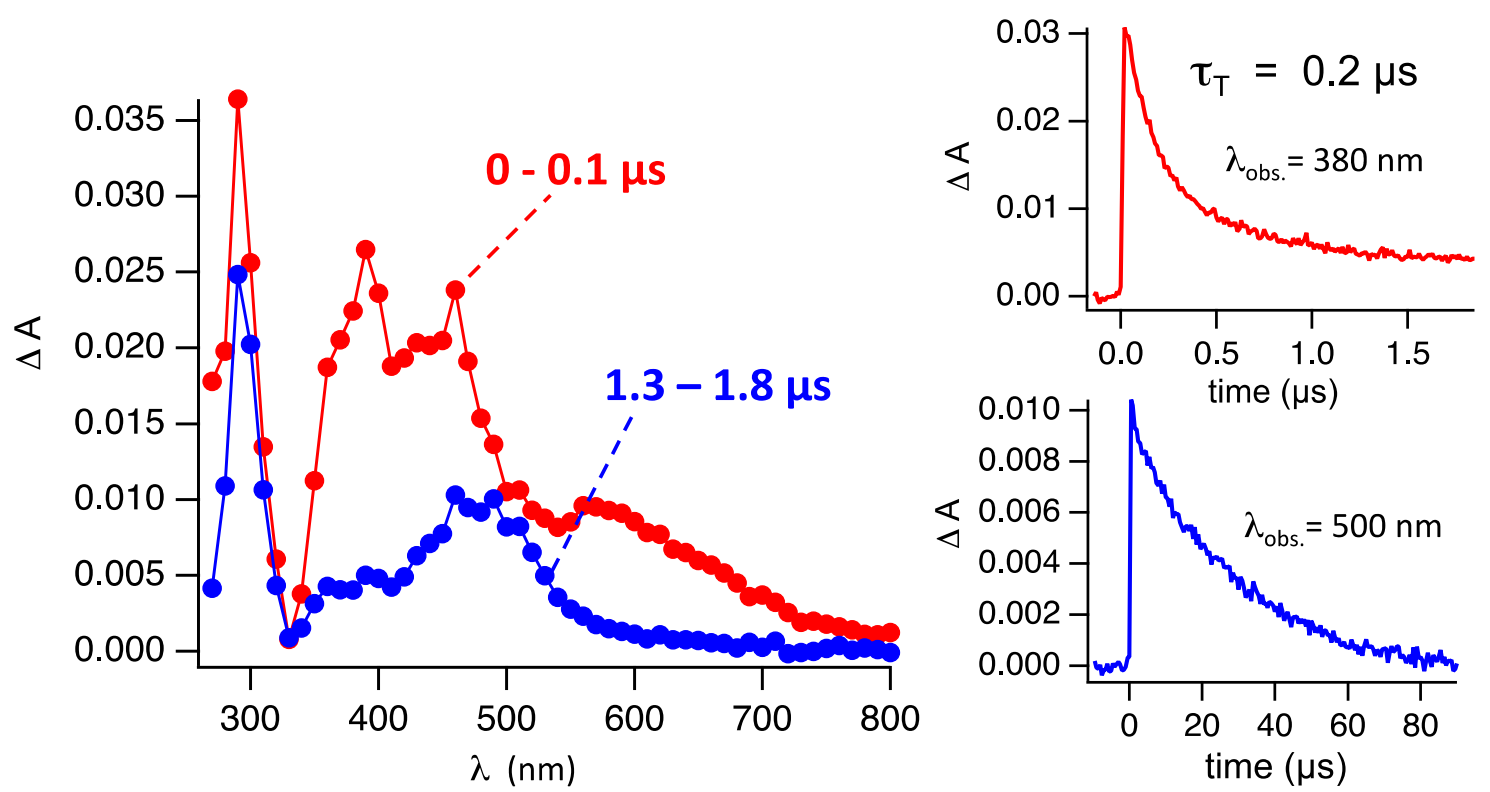

Figure 2. Left: Transient absorption spectra of AQS in deoxygenated aqueous solution at different delay times after the laser pulse $(355 \mathrm{~nm}, 7 \mathrm{~ns}$ pulse width). Right: Decay traces at selected wavelength.
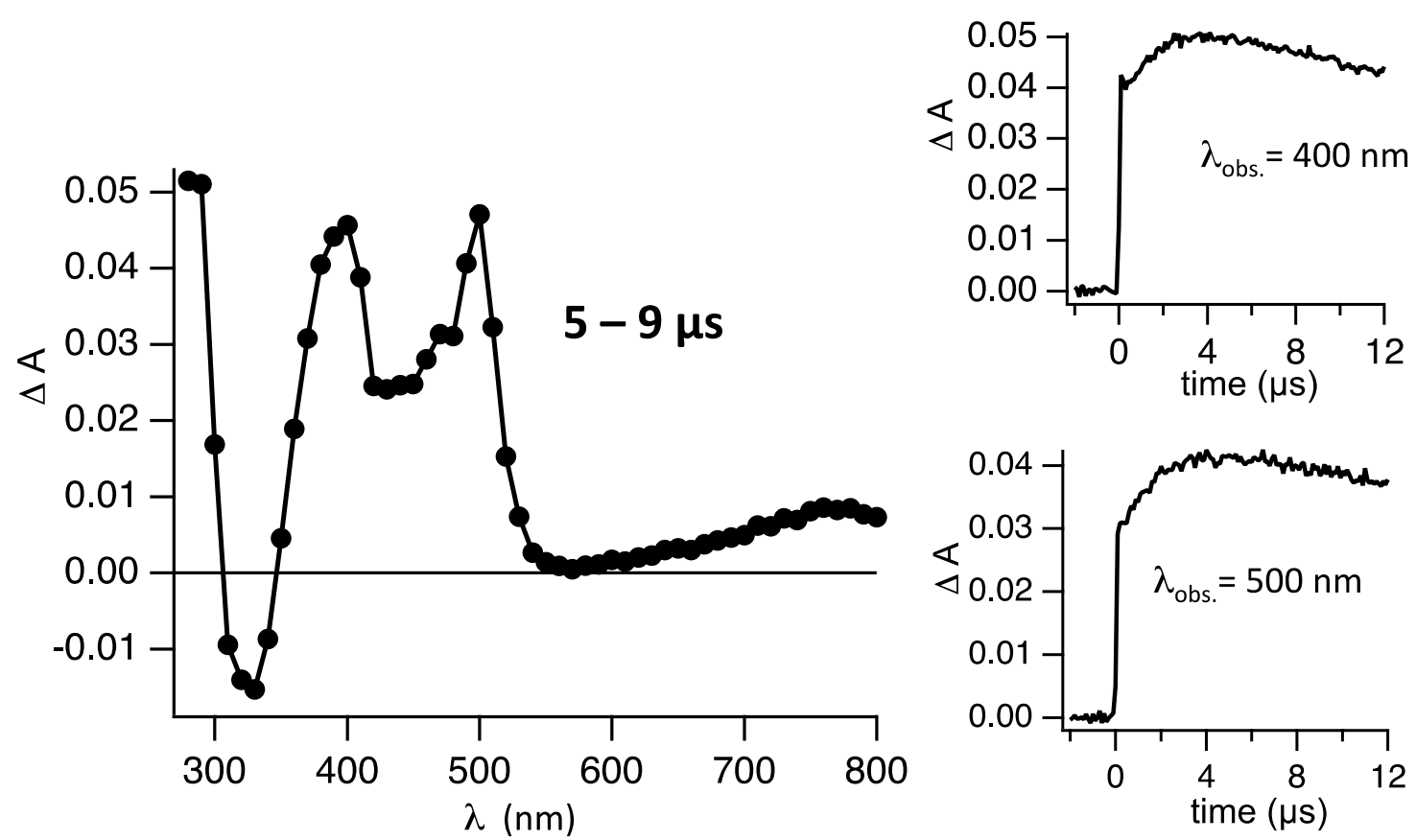

Figure 3. Left: Transient absorption spectrum of AQS in the presence of MDEA (10 mM) in deoxygenated aqueous solution recorded at $5-9 \mu$ s after the laser pulse $(355 \mathrm{~nm}, 7 \mathrm{~ns}$ pulse width). Right: Decay traces at selected wavelength. 


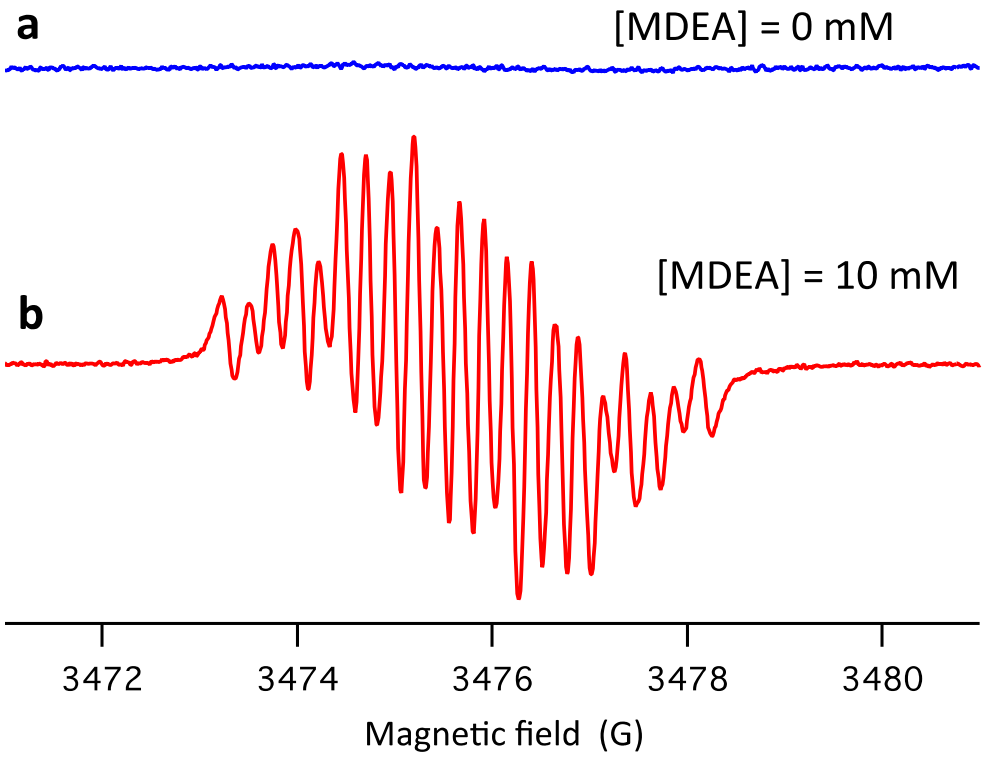

Figure 4. X-band EPR spectra recorded during irradiation of deoxygenated aqueous solutions of AQS in the absence (a) and presence (b) of MDEA (10 mM).

Photorheological behavior of the hydrogels. Photorheological measurements were performed to investigate the reaction kinetics of the system containing A-PEI as a crosslinker in comparison with the native reference sample without A-PEI (Figure 5). The reference sample shows a low reactivity and slow polymerization rate which could be explained by considering the low monomer concentration in the liquid formulation, with a limited ratio of bis-acrylamide crosslinker with respect to the monofunctional acrylamide. A long inhibition time (> $60 \mathrm{~s}$ ) was observed where no variation of the G' modulus is recorded: this indicates that the slow growth of a loosely network that, after 4 minutes of irradiation presents a relatively low modulus $(\sim 5$ $\times 10^{3} \mathrm{~Pa}$ ). In contract, the addition of the multifunctional crosslinker A-PEI induces an increase of the crosslinking reaction, which is reflected in a decreased inhibition time followed by an instantaneous increase of the G' value by two orders of magnitude. A further increase of the elastic modulus is observed upon light exposure and a plateau is reached after $\sim 4$ minutes of irradiation. Interestingly, the final $G^{\prime}$ value $\left(1 \times 10^{5} \mathrm{~Pa}\right)$ is $\sim 20$ times higher than for the reference sample; such value is in line with other hydrogels described in literature for similar applications [40]. The improvement of the reaction speed is due to the combined effect of the higher concentration of monomers in the formulation in addition to the availability of the multifunctional crosslinker (A-PEI). Similar results with the same trend have reported e.g. the increase of G' modulus and the reduction of the induction time when acrylamide is combined with a bifunctional crosslinker [61, 62]. 
The physico-chemical properties of the photoinduced acrylamide-based gels (swelling degree, $\mathbf{M}_{\mathrm{c}}$ and water content) are summarized in Table 2. Table 2 shows that the addition of A-PEI into the gels (in comparison with the reference "R-Acryl") induces a more flexible network with $\mathrm{M}_{\mathrm{c}}$ around $4681 \mathrm{~g} / \mathrm{mol}$, which physically allows water to diffuse inside the gel, thus increasing the swelling ratio (Figure 6) and the weight percent of water content (Figure 7) of the "A-PEI" gels (from 65.1 to $79.6 \%$ ). The swelling equilibrium is reached in less than 30 min. These phenomena may reflect the higher hydrophilic character of the A-PEI chains compared to acrylamide-derived polymers and also point out the lower crosslink density of the "A-PEI" materials in comparison with the materials without A-PEI. Such a trend was previously described by Versace et al. with the introduction of chitosan polymeric chains into PEGdiacrylate gels [40]. The swelling of the "A-PEI" gels in water permit bacteria to come into contact with the quaternary ammonium groups, increasing thus the chance to kill bacteria.

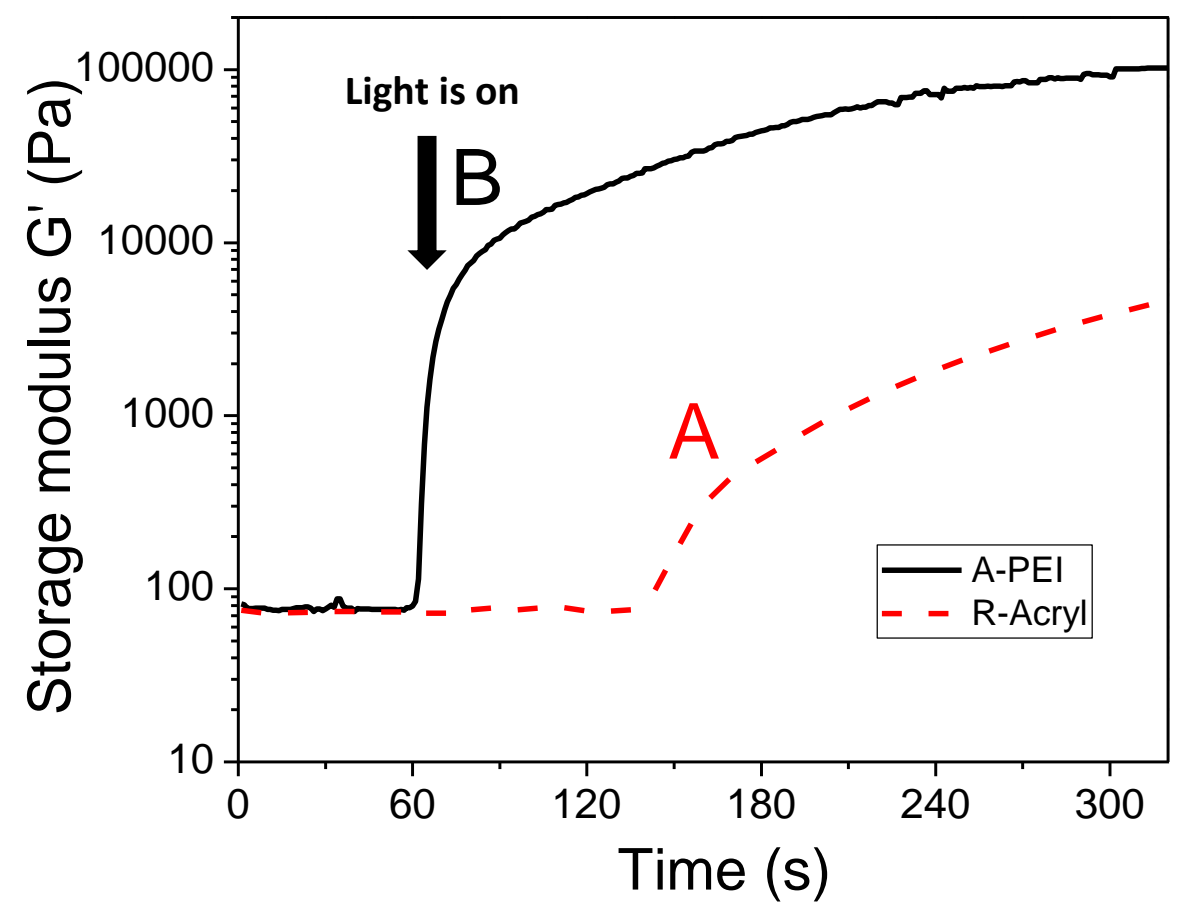

Figure 5. Photorheology of A) the reference "R-Acryl" and B) "A-PEI" formulations using an UV-A irradiation (Light intensity $=25 \mathrm{~mW} / \mathrm{cm}^{2}$ ). 
Table 2. Physico-chemical properties of the photosynthesized acrylamide-based gels

\begin{tabular}{|c|c|c|c|}
\hline Samples & $\begin{array}{c}\text { Swelling ratio } \\
(\%)\end{array}$ & $\mathrm{M}_{\mathrm{c}}{ }^{\mathrm{a}}\left(\mathrm{g} \cdot \mathrm{mol}^{-1}\right)$ & $\mathrm{Q}_{\mathrm{H} 2 \mathrm{O}}{ }^{\mathrm{b}}(\%)$ \\
\hline "R-Acryl" & $324 \pm 64$ & $629 \pm 20$ & $65.1 \pm 1.5$ \\
\hline "A-PEI" & $500 \pm 62$ & $4682 \pm 1579$ & $79.6 \pm 3.1$ \\
\hline
\end{tabular}

a: Molecular weight between crosslinks, b: Water Content at the equilibrium

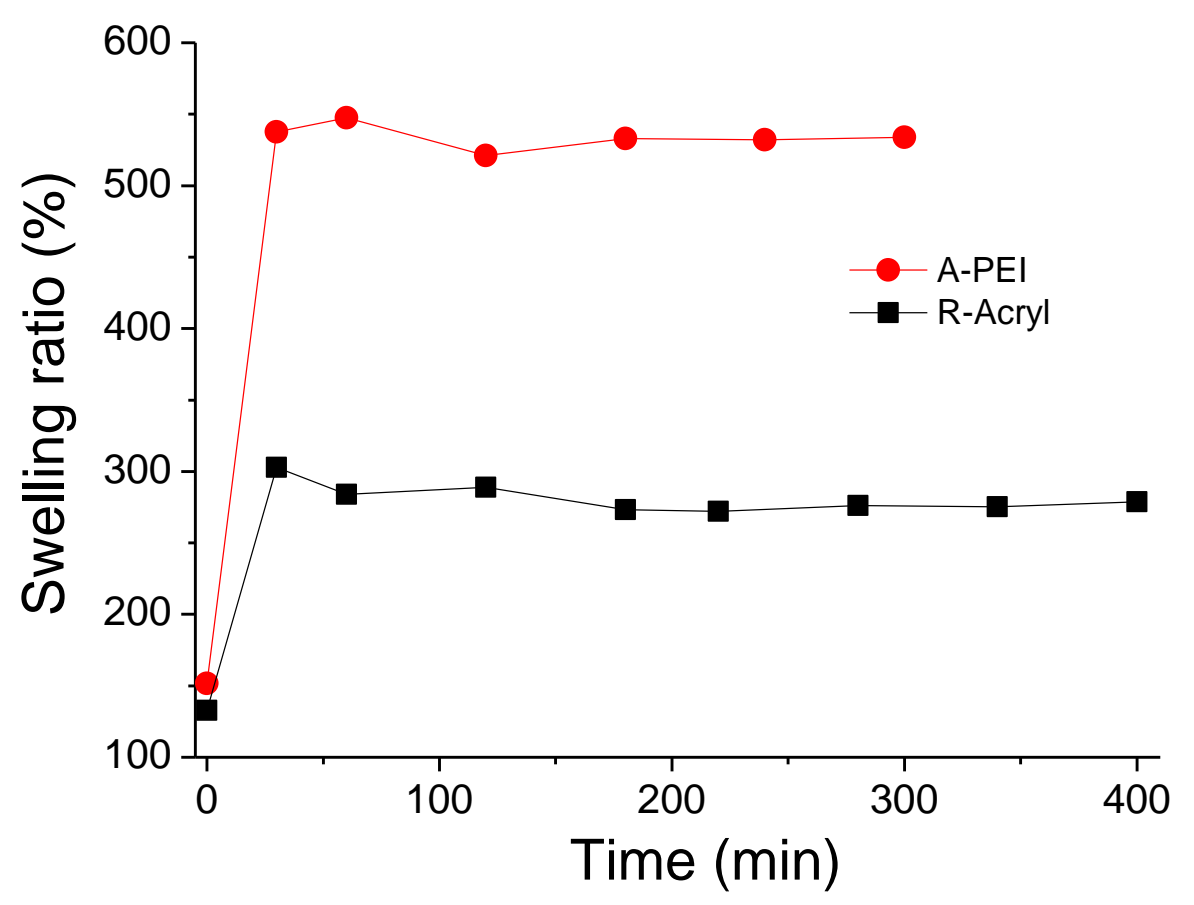

Figure 6. Swelling ratio (\%) as a function of time for the reference "R-Acryl" and the "A-PEI" materials. 


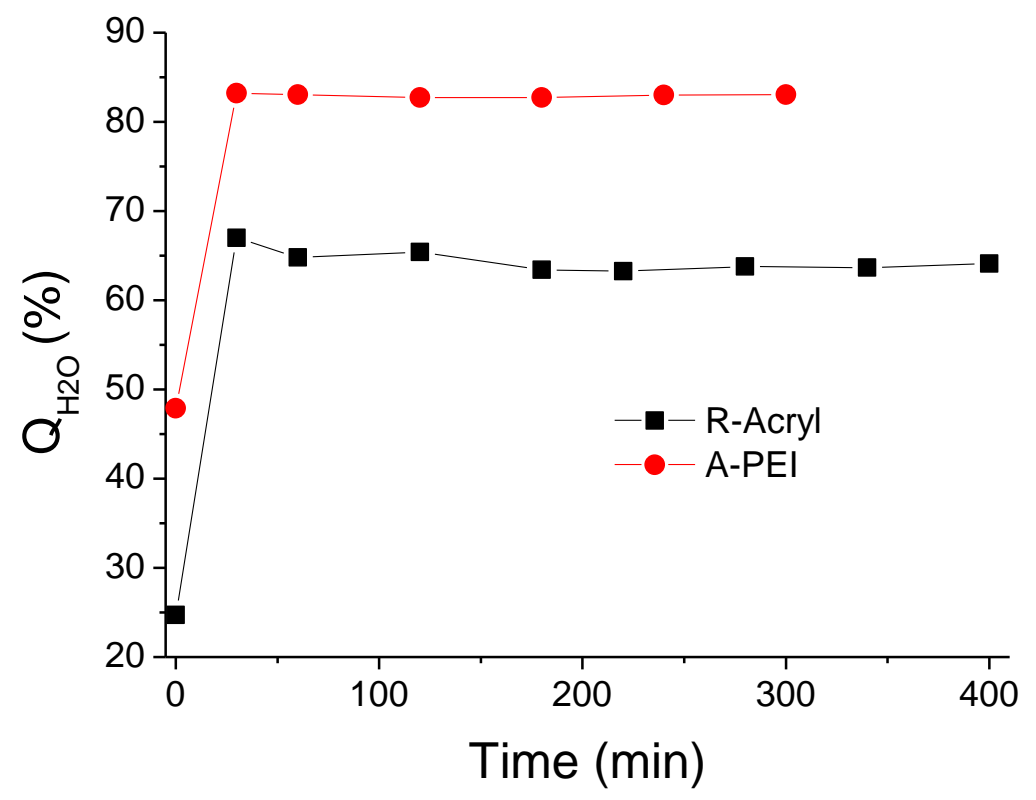

Figure 7. Water content $\left(\mathrm{Q}_{\mathrm{H} 2 \mathrm{O}}\right.$ in \%) as a function of time for the reference "R-Acryl" and the "A-PEI" materials.

The chemical nature of the functions available at the surface of the photo-induced materials with and without A-PEI were observed by XPS measurements. Two XPS survey spectra and XPS spectra of the N1s core levels of both materials are described in Figure 8. The XPS spectra of C1s, O1s core levels, and the deconvolution of the N1s spectra of the two photoinduced materials are depicted in supporting information (Figures S8, S9 and S10). The C1s XPS spectrum for the reference "R-Acryl" hydrogel show three peaks [63, 64] (Figure S8): the first peak $(284.69 \mathrm{eV})$ is attributed to the carbon aliphatic chain $(\underline{\mathrm{C}}-\mathrm{C}$ or $\underline{\mathrm{C}}-\mathrm{H})$, the second peak corresponds to the carbon covalently link to nitrogen $[65,66](\underline{\mathrm{C}}-\mathrm{N}, \mathrm{BE}=286.14 \mathrm{eV})$ and the last peak is assigned to the $\underline{\mathrm{C}}=\mathrm{O}$ chemical bond with $\mathrm{BE}=287.9 \mathrm{eV}[64,65]$. The addition of A-PEI leads to a new $\mathrm{C} 1 \mathrm{~s}$ XPS spectrum (Figure S8): the assigned position of $\underline{\mathrm{C}}-\mathrm{N}$ and $\underline{\mathrm{C}}=\mathrm{O}$ in $\mathrm{C} 1 \mathrm{~s}$ spectrum are $285.95 \mathrm{eV}$ and $287.3 \mathrm{eV}$, respectively. The slight difference of the $\mathrm{C} 1 \mathrm{~s}$ binding energy (in the carbonyl group) between the reference sample ("R-Acryl") and the "APEI" materials is attributed to the presence of hydrogen bonding. Indeed, the increase of $\mathrm{H}$ bonding (in the reference "R-Acryl" material) decrease the electronic density around the carbon atom, thus increasing the difficulty to abstract the valence electrons of the carbon atom, and resulting in the increase of its binding energy [67]. The resolved O1s spectrum show an additional signal [63] when A-PEI is introduced in the hydrogel: the C-O chemical bonds is observed at $531.8 \mathrm{eV}$ both in the reference "R-Acryl" and "A-PEI" samples, the second peak at 
$533.4 \mathrm{eV}$ is attributed to the hydrogen bonding of oxygens with amino groups in the "A-PEI" hydrogel (Figure S9). Interestingly, two N1s signals are observed in the "A-PEI" material in comparison with that of the reference "R-Acryl" (Figure S10). The first peak at $399.1 \mathrm{eV}$ confirms the presence of $\mathrm{C}-\underline{\mathrm{N}}$ bond and a second peak is attributed to the $\mathrm{C}-\underline{\mathrm{N}}^{+}$bond at 401.4 $\mathrm{eV}$. This last N1s signal, which is not observed in the reference "R-Acryl", is likely due to the presence of A-PEI at the surface of the material. The presence of ammonium moieties at the surface of the "A-PEI" hydrogels justifies their use as antibacterial materials against E. coli and S. aureus.

Antibacterial tests. Reference "R-Acryl" and "A-PEI" hydrogels were introduced during $3 \mathrm{~h}$ into bacterial solutions. The number of colonies forming units (CFUs) at the surface of both materials were evaluated by the counting method (Figure 9) and confocal fluorescence images (Figure 10) were additionally performed to evaluate the mortality rate of the bacteria into the non-adhered bacterial solution in contact with the materials. Interestingly, the addition of the A-PEI crosslinker favors the anti-adherence properties of the resulting materials. Indeed, the CFUs of E. coli and $S$. aureus drastically decrease by a factor of 30 and a factor of 6 , respectively when A-PEI is introduced in comparison with that of the reference "R-Acryl". One can note that the reference "R-Acryl" did not demonstrate any cytotoxicity as described by many previous studies [39]. Fluorescence experiments on the surface of the reference "R-acryl" materials revealed that bacteria are alive whatever the strains used (Figure S11). Additional fluorescence results have demonstrated that more than $80 \%$ of the non-adhered bacteria which were in contact with the surface of the "A-PEI" materials were dead. These results are in accordance with literature data [68-71]; indeed, the positive charge of quaternary ammonium groups interact with the negatively charged bacteria wall, due to teichoic acids in Gram-positive cells and phospholipidic outer membrane in Gram-negative ones. Such interactions lead to penetration and disruption of the bacteria wall, increasing thus the permeability $\left(\mathrm{K}^{+}\right.$loss $)$and electrolyte balance disorder leading to the cytolysis. 

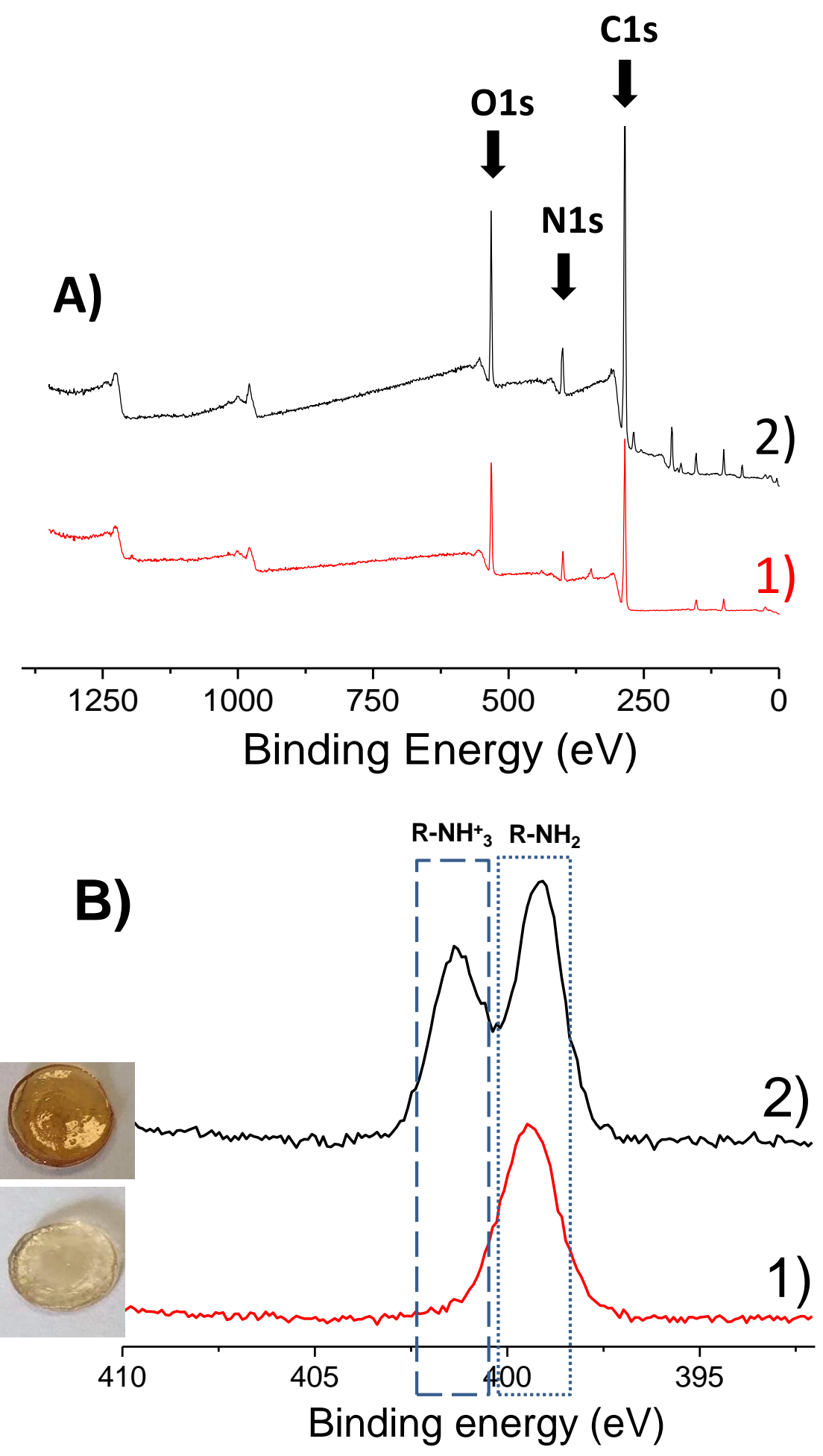

Figure 8. A) XPS survey spectrum and B) XPS spectrum of the N1s core level of 1) the reference "R-Acryl" material and 2) the "A-PEI" material. Optical images of both materials are displayed in B). 


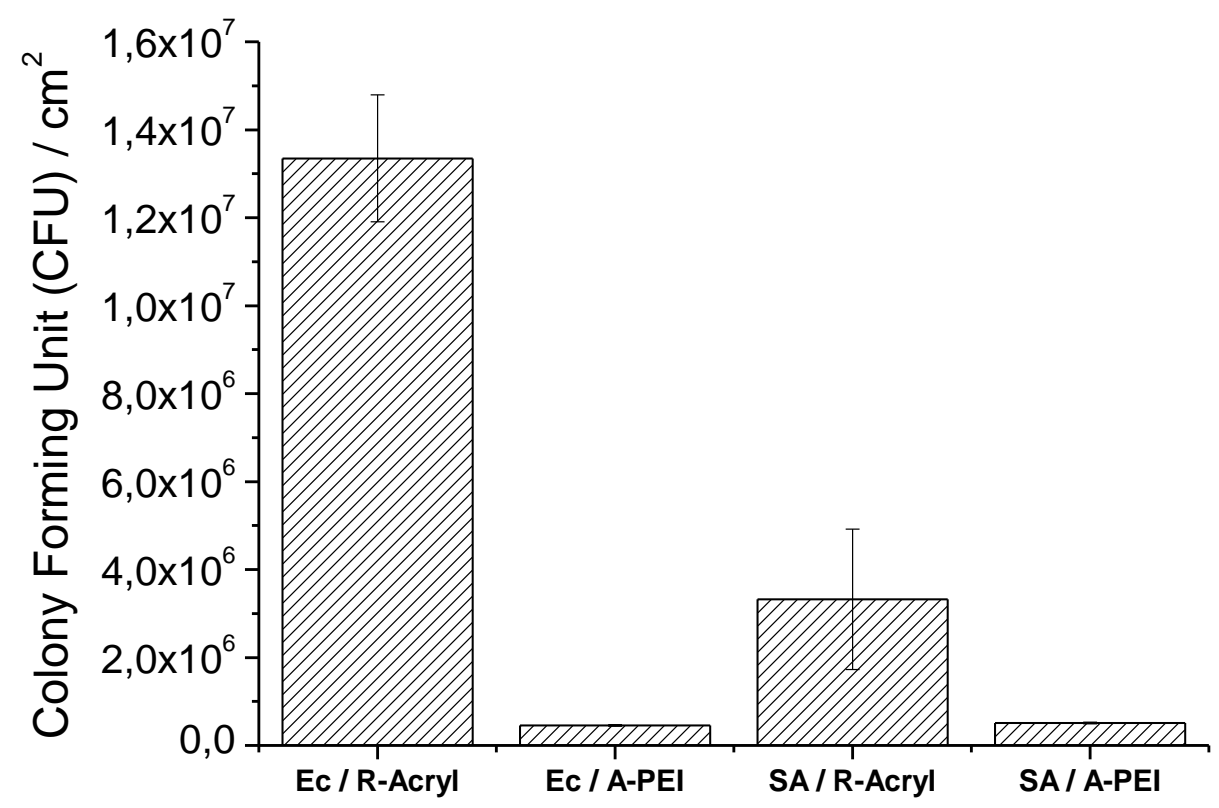

Figure 9. Comparison of the anti-adherence properties against E. coli and S. aureus on the reference "R-Acryl" materials and on the "A-PEI" materials after $3 \mathrm{~h}$ of incubation. Data are shown as mean plus standard deviation, $\mathrm{n}=3$. Results indicate significant difference obtained by t-test $(\mathrm{P}<0.05)$.
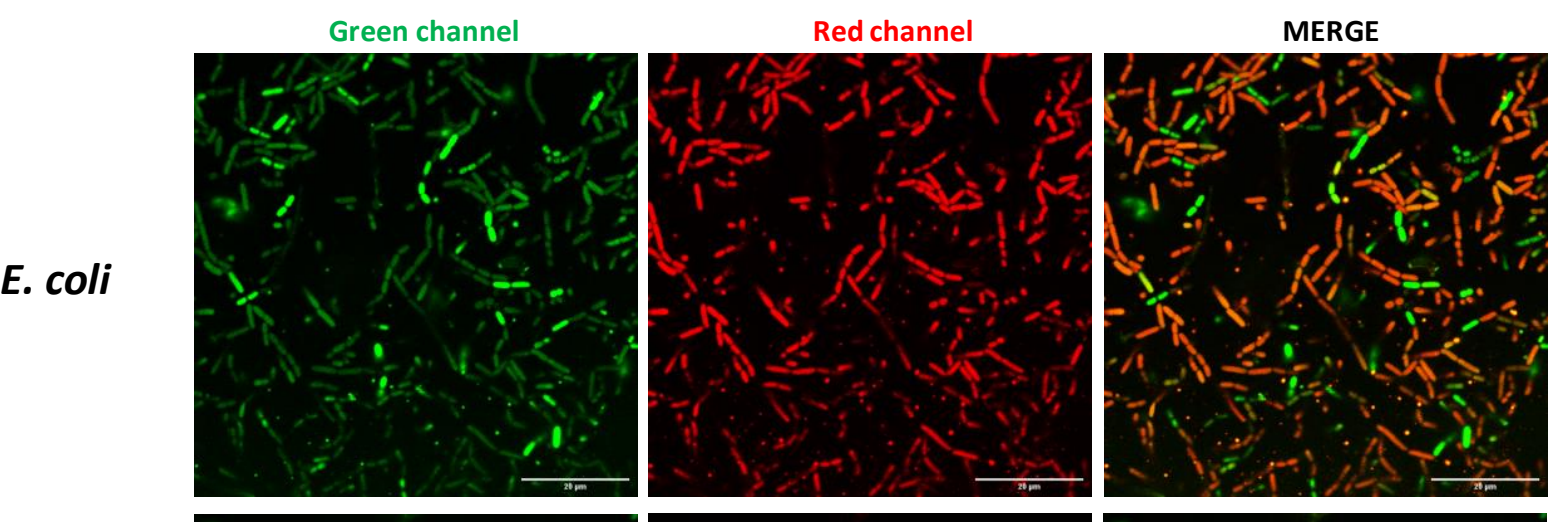

\section{S. aureus}
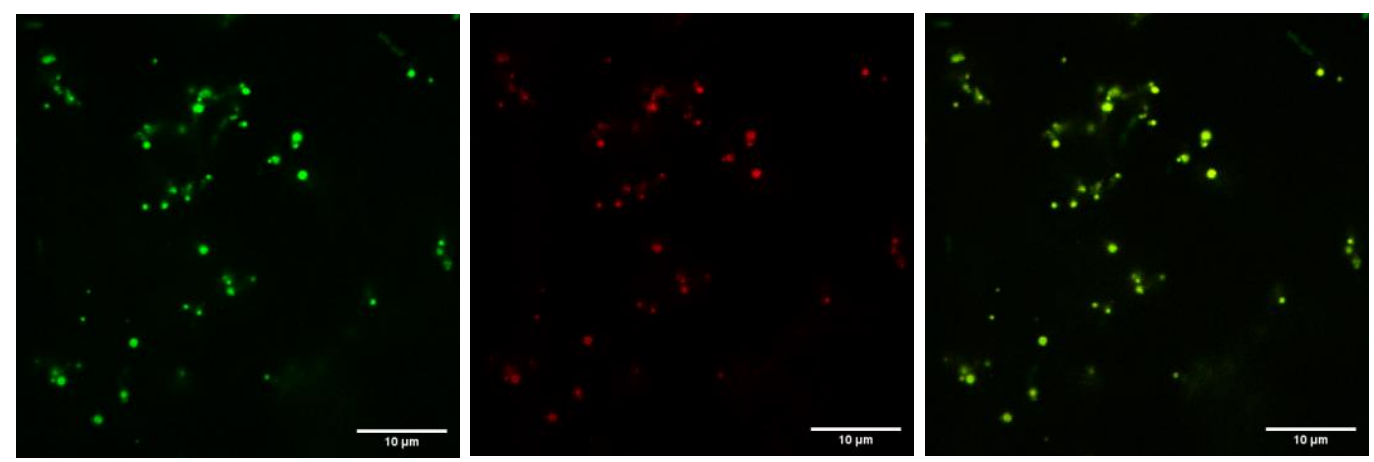

Figure 10. Confocal fluorescence images of non-adhered bacteria solution which incubated in contact with the "A-PEI" hydrogel. Green channel corresponds to Syto 9 labelling (dead and live cells) and red channel to PI labelling (dead cells). 
Conclusion. In this study, a new photoactivable material based on polyethylene imine bearing allyl moieties was synthesized, and used as a photo-crosslinker for the development of a new hydrogel. Photocrosslinking was achieved with a new water-based photoinitiating system containing AQS and MDEA. As shown by laser flash photolysis and EPR spectroscopy, photoexcitation of AQS generates triplet states which react with a rate constant near diffusion control with MDEA to produce highly reactive $\alpha$-aminoalkyl radicals in aqueous medium. Interestingly, the AQS/MDEA photoinitiating system allows the photopolymeriation of acrylamide derivatives under air in water. The addition of the multifunctional crosslinker PEI allyl-derivative also results in a faster crosslinking reaction under LED@385 nm exposure under air and the formation of an antibacterial hydrogel. The presence of the multiple quaternary ammonium groups at the surface of the PEI-based hydrogel induces an inhibition of the adherence of bacteria and lead to their death.

\section{Acknowledgements}

Dr. Davy-Louis Versace would like to thank French National Agency (ANR, sPECTRAL projet), ICMPE and UPEC for financial supports. The work @ ISMO has been supported by the Region Ile-de-France in the framework of DIM Nano-K; by LabEx CHARMMMAT; by fédération Lumière Matière (LUMAT FR2764). Miaobo PAN thanks CSC for PhD scholarship. We thank the Centre de Photonique pour la Biologie et les Matériaux (CPBM) of the Centre Laser de l'Université Paris-Sud (CLUPS/LUMAT FR2764, Orsay, France) and Ms Ludivine Houel-Renault for allowing us to use the confocal microscope and L2 microbiology facilities.

\section{REFERENCES}

[1] R.M. Klevens, J.R. Edwards, C.L. Richards, T.C. Horan, R.P. Gaynes, D.A. Pollock, D.M. Cardo, Estimating Health Care-Associated Infections and Deaths in U.S. Hospitals, 2002, Public Health Reports 122(2) (2007) 160-166.

[2] S.S. Magill, J.R. Edwards, W. Bamberg, Z.G. Beldavs, G. Dumyati, M.A. Kainer, R. Lynfield, M. Maloney, L. McAllister-Hollod, J. Nadle, S.M. Ray, D.L. Thompson, L.E. Wilson, S.K. Fridkin, Multistate Point-Prevalence Survey of Health Care-Associated Infections, N. Engl. J. Med. 370(13) (2014) 1198-1208.

[3] P.W. Stone, M. Pogorzelska-Maziarz, C.T.A. Herzig, L.M. Weiner, E.Y. Furuya, A. Dick, E. Larson, State of infection prevention in US hospitals enrolled in the National Health and Safety Network, Am. J. Infect. Control 42(2) (2014) 94-99.

[4] N. Graves, K. Halton, D. Lairson, Economics and preventing hospital-acquired infection: broadening the perspective., Infect. Control Hosp. Epidemiol. 28(2) (2007) 178-184. 
[5] P.W. Stone, E. Larson, L.N. Kawar, A systematic audit of economic evidence linking nosocomial infections and infection control interventions: 1990-2000., Am. J. Infect. Control. 30(3) (2002) 145-152.

[6] M. Condat, C. Helary, T. Coradin, P. Dubot, J. Babinot, M. Faustini, S.A. Andaloussi, E. Renard, V. Langlois, D.-L. Versace, Design of cytocompatible bacteria-repellent bio-based polyester films via an aqueous photoactivated process, J. Mater. Chem. B 4(16) (2016) 28422850.

[7] P. Sautrot-Ba, J.-P. Malval, M. Weiss-Maurin, J. Paul, A. Blacha-Grzechnik, S. Tomane, P.-E. Mazeran, J. Lalevée, V. Langlois, D.-L. Versace, Paprika, Gallic Acid, and Visible Light: The Green Combination for the Synthesis of Biocide Coatings, ACS Sustain. Chem. Eng. 6(1) (2018) 104-109.

[8] D.-L. Versace, G. Moran, M. Belqat, A. Spangenberg, R. Méallet-Renault, S. AbbadAndaloussi, V. Brezová, J.-P. Malval, Highly Virulent Bactericidal Effects of Curcumin-Based $\mu$-Cages Fabricated by Two-Photon Polymerization, ACS Appl. Mater. Interfaces 12(4) (2020) 5050-5057.

[9] P. Sautrot-Ba, S. Jockusch, J.-P. Malval, V. Brezová, M. Rivard, S. Abbad-Andaloussi, A. Blacha-Grzechnik, D.-L. Versace, Quinizarin Derivatives as Photoinitiators for Free-Radical and Cationic Photopolymerizations in the Visible Spectral Range, Macromolecules 53(4) (2020) 1129-1141.

[10] D.-L. Versace, Y. Yagci, A. Blacha-Grzechnik, N. Bogliotti, V. Brezova, J.-P. Malval, M. Presset, H. Marcille, Diphenyl Functional Porphyrins and Their Metal Complexes as VisibleLight Photoinitiators for Free-Radical, Cationic and Thiol-Ene Polymerizations, Polym. Chem. (2020).

[11] D.-L. Versace, J. Ramier, D. Grande, S.A. Andaloussi, P. Dubot, N. Hobeika, J.-P. Malval, J. Lalevee, E. Renard, V. Langlois, Versatile Photochemical Surface Modification of Biopolyester Microfibrous Scaffolds with Photogenerated Silver Nanoparticles for Antibacterial Activity, Adv. Healthcare Mater. 2(7) (2013) 1008-1018.

[12] C. Lorenzini, A. Haider, I.-K. Kang, M. Sangermano, S. Abbad-Andalloussi, P.-E. Mazeran, J. Lalevée, E. Renard, V. Langlois, D.-L. Versace, Photoinduced Development of Antibacterial Materials Derived from Isosorbide Moiety, Biomacromolecules 16(3) (2015) 683-694.

[13] M. Condat, P.E. Mazeran, J.P. Malval, J. Lalevée, F. Morlet-Savary, E. Renard, V. Langlois, S. Abbad Andalloussi, D.L. Versace, Photoinduced curcumin derivative-coatings with antibacterial properties, RSC Adv. 5(104) (2015) 85214-85224.

[14] P. Sautrot-Ba, A. Al Mousawi, J. Lalevée, P.-E. Mazeran, S.J. Park, I.-K. Kang, M. Laurent-Brocq, V. Langlois, D.-L. Versace, Copper Complex: A Key Role in the Synthesis of Biocidal Polymer Coatings, Chem. Africa 2(2) (2019) 241-251.

[15] L. Breloy, C.A. Ouarabi, A. Brosseau, P. Dubot, V. Brezova, S. Abbad Andaloussi, J.-P. Malval, D.-L. Versace, $\beta$-Carotene/Limonene Derivatives/Eugenol: Green Synthesis of Antibacterial Coatings under Visible-Light Exposure, ACS Sustain. Chem. Eng. 7(24) (2019) 19591-19604.

[16] T. Modjinou, D.L. Versace, S.A. Andaloussi, V. Langlois, E. Renard, Co-Networks Poly(hydroxyalkanoates)-Terpenes to Enhance Antibacterial Properties, Bioengineering (Basel) 7(1) (2020) 13.

[17] J.C. Tiller, Antimicrobial Surfaces, in: H. Börner, J.F. Lutz (Eds.), Bioactive Surfaces. Advances in Polymer Science, Springer, Berlin, Heidelberg, 2010, pp. 193-217.

[18] I. Francolini, C. Vuotto, A. Piozzi, G. Donelli, Antifouling and antimicrobial biomaterials: an overview., APMIS 125(4) (2017) 392-417 
[19] H. Koo, R.N. Allan, R.P. Howlin, P. Stoodley, L. Hall-Stoodley, Targeting microbial biofilms: current and prospective therapeutic strategies, Nature Rev. Microbiol. 15(12) (2017) $740-755$.

[20] K. Vasilev, A. Cavallaro, P. Zilm, Special Issue: Antibacterial Materials and Coatings, Molecules 23(3) (2018) 585.

[21] S. Mahira, A. Jain, W. Khan, A.J. Domb, Chapter 1 Antimicrobial Materials-An Overview, Antimicrobial Materials for Biomedical Applications, The Royal Society of Chemistry 2019, pp. 1-37.

[22] X. Li, B. Wu, H. Chen, K. Nan, Y. Jin, L. Sun, B. Wang, Recent developments in smart antibacterial surfaces to inhibit biofilm formation and bacterial infections, J. Mater. Chem. B 6(26) (2018) 4274-4292.

[23] G.M. Manecka, J. Labrash, O. Rouxel, P. Dubot, J. Lalevée, S.A. Andaloussi, E. Renard, V. Langlois, D.L. Versace, Green Photoinduced Modification of Natural Poly(3hydroxybutyrate-co-3-hydroxyvalerate) Surface for Antibacterial Applications, ACS Sustain. Chem. Eng. 2(4) (2014) 996-1006.

[24] S. El Habnouni, V. Darcos, X. Garric, J.-P. Lavigne, B. Nottelet, J. Coudane, Mild Methodology for the Versatile Chemical Modification of Polylactide Surfaces: Original Combination of Anionic and Click Chemistry for Biomedical Applications, Adv. Funct. Mater. 21(17) (2011) 3321-3330.

[25] P. Feiertag, M. Albert, E.-M. Ecker-Eckhofen, G. Hayn, H. Hönig, H.W. Oberwalder, R. Saf, A. Schmidt, O. Schmidt, D. Topchiev, Structural Characterization of Biocidal Oligoguanidines, Macromol. Rapid Comm. 24(9) (2003) 567-570.

[26] M.A. Schmitt, B. Weisblum, S.H. Gellman, Unexpected Relationships between Structure and Function in $\alpha, \beta$-Peptides: Antimicrobial Foldamers with Heterogeneous Backbones, J. Am. Chem. Soc. 126(22) (2004) 6848-6849.

[27] M.A. Schmitt, B. Weisblum, S.H. Gellman, Interplay among Folding, Sequence, and Lipophilicity in the Antibacterial and Hemolytic Activities of $\alpha / \beta$-Peptides, J. Am. Chem. Soc. 129(2) (2007) 417-428.

[28] E.-R. Kenawy, F.I. Abdel-Hay, A.E.-R.R. El-Shanshoury, M.H. El-Newehy, Biologically active polymers: synthesis and antimicrobial activity of modified glycidyl methacrylate polymers having a quaternary ammonium and phosphonium groups, J. Control. Release 50(1) (1998) 145-152.

[29] Y. Chang, W. Yandi, W.-Y. Chen, Y.-J. Shih, C.-C. Yang, Y. Chang, Q.-D. Ling, A. Higuchi, Tunable Bioadhesive Copolymer Hydrogels of Thermoresponsive Poly(N-isopropyl acrylamide) Containing Zwitterionic Polysulfobetaine, Biomacromolecules 11(4) (2010) 11011110 .

[30] P. Podsiadlo, S. Paternel, J.-M. Rouillard, Z. Zhang, J. Lee, J.-W. Lee, E. Gulari, N.A. Kotov, Layer-by-Layer Assembly of Nacre-like Nanostructured Composites with Antimicrobial Properties, Langmuir 21(25) (2005) 11915-11921.

[31] T. Modjinou, H. Rodriguez-Tobias, G. Morales, D.-L. Versace, V. Langlois, D. Grande, E. Renard, UV-cured thiol-ene eugenol/ZnO composite materials with antibacterial properties, RSC Adv. 6(91) (2016) 88135-88142.

[32] Z. Tang, N.A. Kotov, S. Magonov, B. Ozturk, Nanostructured artificial nacre, Nat. Mater. 2(6) (2003) 413-418.

[33] K.D. Park, Y.S. Kim, D.K. Han, Y.H. Kim, E.H.B. Lee, H. Suh, K.S. Choi, Bacterial adhesion on PEG modified polyurethane surfaces, Biomaterials 19(7) (1998) 851-859.

[34] J. Genzer, K. Efimenko, Recent developments in superhydrophobic surfaces and their relevance to marine fouling: a review, Biofouling 22(5) (2006) 339-360.

[35] S. Finnegan, S.L. Percival, Clinical and Antibiofilm Efficacy of Antimicrobial Hydrogels, Adv. Wound Care (New Rochelle) 4(7) (2015) 398-406. 
[36] V.W. Ng, J.M. Chan, H. Sardon, R.J. Ono, J.M. García, Y.Y. Yang, J.L. Hedrick, Antimicrobial hydrogels: a new weapon in the arsenal against multidrug-resistant infections, Adv. Drug Deliv. Rev. 78 (2014) 46-62.

[37] C. Ghobril, M.W. Grinstaff, The chemistry and engineering of polymeric hydrogel adhesives for wound closure: a tutorial, Chem. Soc. Rev. 44(7) (2015) 1820-1835.

[38] S. Li, S. Dong, W. Xu, S. Tu, L. Yan, C. Zhao, J. Ding, X. Chen, Antibacterial Hydrogels, Adv. Sci. 5(5) (2018) 1700527.

[39] K. Yang, Q. Han, B. Chen, Y. Zheng, K. Zhang, Q. Li, J. Wang, Antimicrobial hydrogels: promising materials for medical application, Int. J. Nanomed. 13 (2018) 2217-2263.

[40] P. Sautrot-Ba, N. Razza, L. Breloy, S.A. Andaloussi, A. Chiappone, M. Sangermano, C. Hélary, S. Belbekhouche, T. Coradin, D.L. Versace, Photoinduced chitosan-PEG hydrogels with long-term antibacterial properties, J. Mater. Chem. B 7(42) (2019) 6526-6538.

[41] M. Uygun, M.U. Kahveci, D. Odaci, S. Timur, Y. Yagci, Antibacterial Acrylamide Hydrogels Containing Silver Nanoparticles by Simultaneous Photoinduced Free Radical Polymerization and Electron Transfer Processes, Macromol. Chem. Phys. 210(21) (2009) $1867-$ 1875.

[42] Y.-H. La, B.D. McCloskey, R. Sooriyakumaran, A. Vora, B. Freeman, M. Nassar, J. Hedrick, A. Nelson, R. Allen, Bifunctional hydrogel coatings for water purification membranes: Improved fouling resistance and antimicrobial activity, J. Membr. Sci. 372(1) (2011) 285-291.

[43] M.U. Kahveci, M. Ciftci, S. Evran, S. Timur, Y. Yagci, Photoinduced in situ formation of clickable PEG hydrogels and their antibody conjugation, Des. Monomers Polym. 18(2) (2015) 129-136.

[44] J.P. Fouassier, J. Lalevée, Photoinitiators for Polymer Synthesis: Scope, Reactivity, and Efficiency, Wiley2013.

[45] S. Chatani, C.J. Kloxin, C.N. Bowman, The power of light in polymer science: photochemical processes to manipulate polymer formation, structure, and properties, Polym. Chem. 5(7) (2014) 2187-2201.

[46] Y. Xue, H. Xiao, Y. Zhang, Antimicrobial Polymeric Materials with Quaternary Ammonium and Phosphonium Salts, Int. J. Mol. Sci. 16(2) (2015) 3626-3655.

[47] Y. Yang, Z. Cai, Z. Huang, X. Tang, X. Zhang, Antimicrobial cationic polymers: from structural design to functional control, Polym. J. 50(1) (2018) 33-44.

[48] P. Elena, K. Miri, Formation of contact active antimicrobial surfaces by covalent grafting of quaternary ammonium compounds, Colloid Surface B 169 (2018) 195-205.

[49] W. Sajomsang, P. Gonil, S. Tantayanon, Antibacterial activity of quaternary ammonium chitosan containing mono or disaccharide moieties: Preparation and characterization, Int. J. Biol. Macromol. 44(5) (2009) 419-427.

[50] G. Gozzelino, D.E. Romero Tobar, N. Chaitiemwong, W. Hazeleger, R. Beumer, Antibacterial Activity of Reactive Quaternary Ammonium Compounds in Solution and in Nonleachable Coatings, J. Food Prot. 74(12) (2011) 2107-2112.

[51] Y. Yagci, S. Jockusch, N.J. Turro, Mechanism of Photoinduced Step Polymerization of Thiophene by Onium Salts: Reactions of Phenyliodinium and Diphenylsulfinium Radical Cations with Thiophene, Macromolecules 40(13) (2007) 4481-4485.

[52] R. Poupart, A. Haider, J. Babinot, I.K. Kang, J.P. Malval, J. Lalevée, S.A. Andalloussi, V. Langlois, D.L. Versace, Photoactivable Surface of Natural Poly(3-hydroxybutyrate-co-3hydroxyvalerate) for Antiadhesion Applications, ACS Biomater. Sci. Eng. 1(7) (2015) 525538.

[53] T.-T.-T. Nguyen, S. Belbekhouche, P. Dubot, B. Carbonnier, D. Grande, From the functionalization of polyelectrolytes to the development of a versatile approach to the synthesis 
of polyelectrolyte multilayer films with enhanced stability, J. Mater. Chem. A 5(46) (2017) 24472-24483.

[54] T.-T.T. Nguyen, S. Belbekhouche, R. Auvergne, B. Carbonnier, D. Grande, Controlled allylation of polyelectrolytes: a deep insight into chemical aspects and their applicability as building blocks for robust multilayer coatings Pure Appl. Chem. 91(6) (2019) 983-995.

[55] I. Loeff, A. Treinin, H. Linschitz, The photochemistry of 9,10-anthraquinone-2-sulfonate in solution. 2. Effects of inorganic anions: quenching vs. radical formation at moderate and high anion concentrations, J. Phys. Chem. 88(21) (1984) 4931-4937.

[56] I. Loeff, A. Treinin, H. Linschitz, Photochemistry of 9,10-anthraquinone-2-sulfonate in solution. 1. Intermediates and mechanism, J. Phys. Chem. 87(14) (1983) 2536-2544.

[57] A. Bedini, E. De Laurentiis, B. Sur, V. Maurino, C. Minero, M. Brigante, G. Mailhot, D. Vione, Phototransformation of anthraquinone-2-sulphonate in aqueous solution, Photochem. Photobiol. Sci. 11(9) (2012) 1445-1453.

[58] J.N. Moore, D. Phillips, R.E. Hester, Time-Resolved Resonance Raman Spectroscopy Applied to the Photochemistry of the Sulfonated Derivatives of 9, 10-Anthraquinone, J. Phys. Chem. 92 (1988) 5619-5627.

[59] J. Ma, Time-resolved laser flash photolysis study on transient reaction between excited triplet state of anthraquinone derivatives (AQS) and 2-deoxythymidine, Natural Sci. 6 (2014) $1-4$.

[60] I. Loeff, S. Goldstein, A. Treinin, H. Linschitz, Interactions of formate ion with triplets of anthraquinone-2-sulfonate, 1,4-naphthoquinone, benzophenone-4-carboxylate and benzophenone-4-sulfonate, J. Phys. Chem. 95(11) (1991) 4423-4430.

[61] D. Calvet, J.Y. Wong, S. Giasson, Rheological Monitoring of Polyacrylamide Gelation: Importance of Cross-Link Density and Temperature, Macromolecules 37(20) (2004) 77627771.

[62] J. Wang, V.M. Ugaz, Using in situ rheology to characterize the microstructure in photopolymerized polyacrylamide gels for DNA electrophoresis, Electrophoresis 27(17) (2006) 3349-3358.

[63] M. Bou, J.M. Martin, T. Le Mogne, L. Vovelle, Chemistry of the interface between aluminium and polyethyleneterephthalate by XPS, Appl. Surf. Sci. 47(2) (1991) 149-161.

[64] L.N. Bùi, M. Thompson, N.B. McKeown, A.D. Romaschin, P.G. Kalman, Surface modification of the biomedical polymer poly(ethylene terephthalate), The Analyst 118(5) (1993) 463-74.

[65] J. Charlier, V. Detalle, F. Valin, C. Bureau, G. Lécayon, Study of ultrathin polyamide-6,6 films on clean copper and platinum, J. Vac. Sci. Technol. A 15(2) (1997) 353-364.

[66] F.S. Ohuchi, S.C. Freilich, Metal polyimide interface: A titanium reaction mechanism, J. Vac. Sci. Technol. A 4(3) (1986) 1039-1045.

[67] L. Li, C.-M. Chan, L.-T. Weng, The effects of specific interactions on the surface structure and composition of miscible blends of poly(vinyl alcohol) and poly(N-vinyl-2-pyrrolidone), Polymer 39(11) (1998) 2355-2360.

[68] T. Ikeda, H. Hirayama, H. Yamaguchi, S. Tazuke, M. Watanabe, Polycationic biocides with pendant active groups: molecular weight dependence of antibacterial activity, Antimicrob. Agents Chemother. 30(1) (1986) 132-136.

[69] T. Ikeda, S. Tazuke, M. Watanabe, Interaction of biologically active molecules with phospholipid membranes: I. Fluorescence depolarization studies on the effect of polymeric biocide bearing biguanide groups in the main chain., BBA - Biomembranes 735(3) (1983) 380386.

[70] P. Broxton, P.M. Woodcock, P. Gilbert, A study of the antibacterial activity of some polyhexamethylene biguanides towards Escherichia coli ATCC 8739., J. Appl. Bacteriol. 54 (1983) 345-353. 
[71] R.C. Goy, S.T.B. Morais, O.B.G. Assis, Evaluation of the antimicrobial activity of chitosan and its quaternized derivative on E. coli and S. aureus growth., Rev. Bras. Farmacogn. 26(1) (2016) 122-127. 